\title{
The Effects of Air Preheating and Fuel/Air Inlet Diameter on the Characteristics of Vortex Flame
}

\author{
Mostafa Khaleghi, ${ }^{1}$ S. E. Hosseini, ${ }^{1}$ M. A. Wahid, ${ }^{1}$ and H. A. Mohammed ${ }^{2}$ \\ ${ }^{1}$ High-Speed Reacting Flow Laboratory, Faculty of Mechanical Engineering, Universiti Teknologi Malaysia (UTM), \\ 81310 Skudai, Johor, Malaysia \\ ${ }^{2}$ Department of Environmental Engineering, College of Engineering, Komar University of Science and Technology (KUST), \\ King Mahmud Circle, Sulaymaniyah, Kurdistan, Iraq
}

Correspondence should be addressed to Mostafa Khaleghi; mostafa26_k@yahoo.com

Received 28 September 2014; Revised 8 April 2015; Accepted 26 April 2015

Academic Editor: David Kubička

Copyright (C) 2015 Mostafa Khaleghi et al. This is an open access article distributed under the Creative Commons Attribution License, which permits unrestricted use, distribution, and reproduction in any medium, provided the original work is properly cited.

\begin{abstract}
The effects of fuel/air inlet diameter as well as air preheating on the flame stability, temperature distribution, pollutant formation, and combustion characteristics of a lab-scaled asymmetric vortex flame have been investigated. A three-dimensional steady-state finite volume solver has been used to solve the governing and energy equations. The solver uses a first-order upwind scheme to discretize the governing equations in the space. The semi-implicit method for pressure linked equations has been applied to couple the pressure to the velocity terms. Several turbulence models were applied to predict the flame temperature and it was found that $K-\varepsilon$ RNG has given the best results in accordance with the experimental results. The results reveal that the inlet air diameter can enhance the thermal properties and reduce the $\mathrm{NO}_{x}$ emission while the inlet fuel diameter has less significant impact. Increasing diameters are accompanied with a pressure drop. It was found that preheating the air and fuel would significantly affect the flame temperature and $\mathrm{NO}_{x}$ emission with constant mass flow rate.
\end{abstract}

\section{Introduction}

Emissions of nitrogen oxides $\left(\mathrm{NO}_{x}\right)$ are allied with a range of environmental anxieties that include increasing ground level ozone, acidification of aquatic systems, forest damage, and formation of fine particles in the atmosphere [1-3]. These anxieties have resulted in a need to reduce emissions in various combustion systems. Vortex combustion has been known for its ability to improve flame stability and decrease $\mathrm{NO}_{x}$ formation $[4,5]$. Vortex combustion is widely employed in furnaces and gas turbine combustors. Due to the wide industrial applications of vortex combustion, there has been a considerable amount of research on such flames, both premixed and nonpremixed. The first discussion of vortex flames was reported in 1998 by Gabler [6]. The turbulent vortex flame was described for the first time in such work by both experimental and computational methods. The major objective of
Gabler's work was to identify the possible reduction in pollutant formation from vortex flames. A concise description of the flame anatomy was presented, and some of the basic features of vortex flames were reported. These features include the enhanced stability near the lean flammability limit of the fuel and some primary temperature profiling. In previous studies, a description of the flame anatomy was presented, and some of the basic features of vortex flames were reported. These features include the enhanced stability near the lean flammability limit of the fuel and some primary temperature profiling $[7,8]$. Recent issues in the vortex combustion could be found in modern gas turbines, which rely on premixed combustion to reduce $\mathrm{NO}_{x}$ emissions but are more sensitive to resonant coupling, leading to instability [9-11]. Gas turbine combustion dynamics have been considered in a series of articles edited by Lieuwen and Yang [12]. Effect of the oxygen concentration, preheating, pressure, and equivalence ratio 
on the vortex flame characteristics of oxy-fuel flames, at an atmospheric pressure, showed that the percentage of $\mathrm{O}_{2}$ in the oxidizer plays a crucial role in the flame stabilization. Flames with lower $\mathrm{O}_{2}$ concentrations were seen to be more sensitive to stoichiometry and preheating temperatures [13]. Vortex interactions play a key role in many practical combustion applications by enhanced mixing, organize the flame region, and improve the flame stabilization process [14]. Around the lower stagnation point for partially premixed swirl flame with the lean blowout, the flame root is inherently unstable near lean blowout due to the presence of high strain rates, featuring frequent extinction and reigniting [15]. The lack of a strong recirculation zone and the shorter residence time within the low-swirl injector is a promising solution for attaining ultralow emissions in gas turbines [16]. Vortex flame is stabled by using cavity as flame holder which is essential for the better performance of the engine and more efficiency of combustion $[17,18]$. The interplay of a vortex pair with a premixed flame provides an important model for premixed turbulent combustion. Investigation of this behavior has proven that the vortex not only stretches and strains the flame, but also scours material from the preheating region in front of the flame and at early times replaces it with inlet gases [19].

In the previous studies of vortex flows, the role of the air/ fuel inlet as well as swirl number is underlined. Conditions giving increase to the central recirculation zone (CRZ) have been surveyed by Beer [20] and Gupta and Lilley [21], who found that this area is formed when the swirl number $\left(S_{n}\right)$ exceeds a certain threshold, with a value of $S_{n} \geq 0.6$ given tentatively. Choi et al. [22] indicated that the CRZ resulted from a swirling flow instability that depends on the level of swirl, tube length, end conditions, and flow exothermicity. The precessing vortex core (PVC) rotates in the flow direction, and its frequency increases linearly with the flow velocity but does not necessarily coincide with the flow rotation rate [23]. The PVC modifies conditions of flame anchoring, and, under similar aerodynamic conditions, flame stabilization is improved by effectively enhancing hot gas recirculation [24, 25]. Saqr et al. [26] analyzed a low-emission combustion process based on the vortex flame concept by computational and experimental investigations of a turbulent asymmetric vortex flame. The three-dimensional reacting flow fields were described using a computational methodology where the $R \varepsilon / k-\varepsilon$ turbulence model and the Eddydissipation combustion model were implemented. The results have shown uniform trend for modified $k-\varepsilon$ and standard $k-\varepsilon$ and it is evident that the vortex flames for a nonpremixed combustion exhibit the characteristics of premixed flames in terms of color and temperature.

The major motivation of the present study is to discover some of the main characteristics of the reactive flow field of the asymmetric vortex flames such as effects of air/fuel inlet diameter and preheating air/fuel on the flame stability, temperature distribution, and pollutant formation. The paper has been motivated by two major concerns. The first concern is the recent growing global trends to reduce nitrogen emission from the industrial and power generation sectors. The second concern is the absence of complete understanding of the aerodynamic stability mechanism of vortex flames. Such absence significantly impedes their practical utilization in different applications.

\section{The Asymmetric Vortex Combustor}

Based on the schematic of the combustor presented in Figure 1, the vortex combustor was designed to enhance the aerodynamics of vortex flames and create a strong vortex field for the flame stabilization. This concept has two inlets for air and two inlets for fuel. The allocation of each pair of air and fuel inlets was designed to allow the mixing between fuel and air to occur in the vicinity of a strong forced vortex field. Such vortex is created by the introduction of the air with a full tangential velocity component to the asymmetric combustor. The fuel and air inlet nozzles were circular in cross section with a diameter of $2 \mathrm{~mm}$ and $5 \mathrm{~mm}$, respectively. The equivalence ratio was controlled by varying the inlet mass flow rate of air and fuel. Methane has been utilized as a fuel. Air and fuel flow rates were measured by columnar flowmeters, and the values were corrected to account for the inlet conditions of both pressure and gas density. Air was supplied at 2-bar pressure from a compressor equipped with a damping tank. Fuel was supplied from a pressurized tank at 2 bars.

\section{Experimental Setup}

The experimental stage was settled to allow direct photography from one plane and intrusive access of gas analyzer for emission and temperature measurements. A schematic of the experimental platform is shown in Figure 2. Air was delivered at 2 bars from a gush tank connected to a single stage reciprocating compressor, equipped with a pressure gauge and regulator. Methane was supplied at 2 bars from a pressurized cylinder. Two columnar flowmeters with flowregulating screw from Cole-Palmer were used to measure the flow rate of fuel and air. Stretchy plastic plumbing was applied to connect the combustor chamber to the fuel-air supply system. A Sony 300 FPS digital camera was installed perpendicular to the outlet plane of the combustor to execute direct photographs for the flame. A TELEGAN Tempest-100 gas analyzer with a stainless steel probe was used to measure the emissions and temperature inside the combustor. To enable the axial movement of the probe, a traverse system was set.

\section{Mathematical Model}

4.1. Governing Equations. The three-dimensional steadystate Favre-averaged governing equations for mass, momentum, species transport, and energy in Cartesian coordinates are given as [27]

$$
\begin{aligned}
\frac{\partial \rho \tilde{u}_{j}}{\partial x_{j}} & =0, \\
\frac{\partial \rho \widetilde{u}_{i} \widetilde{u}_{j}}{\partial x_{j}} & =-\frac{\partial P}{\partial x_{i}}+\frac{\partial}{\partial x_{j}}\left[\left(\mu+\mu_{t}\right)\left(\frac{\partial \widetilde{u}_{i}}{\partial x_{j}}+\frac{\partial \widetilde{u}_{j}}{\partial x_{i}}\right)\right],
\end{aligned}
$$




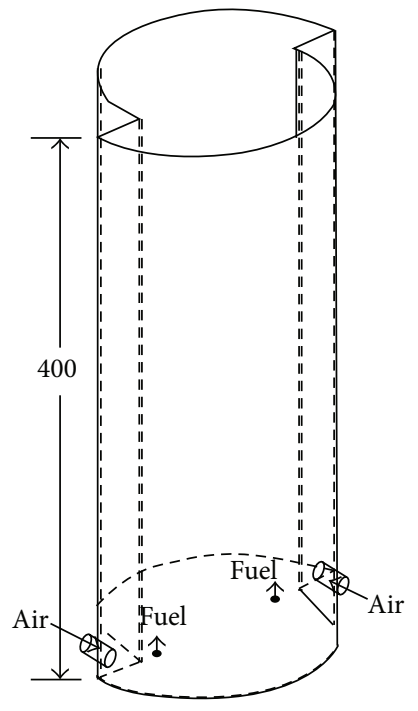

(a)

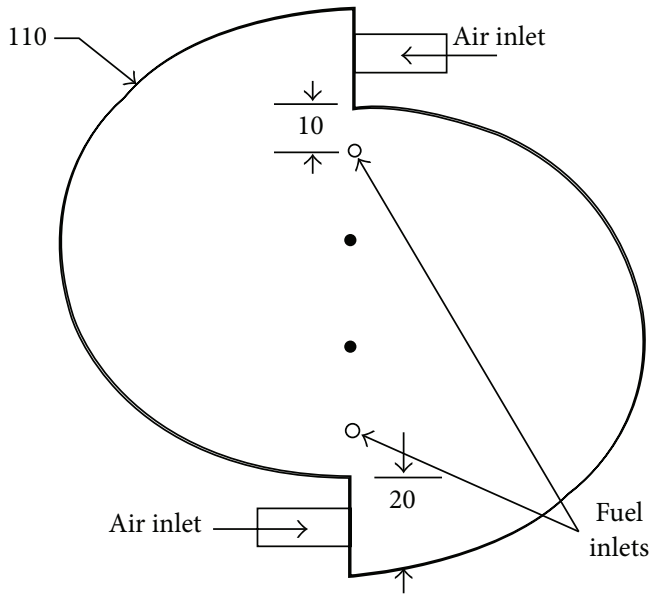

(b)

FIGURE 1: Schematic diagram of the asymmetric combustor: (a) isometric view and (b) top view; all dimensions are in mm.

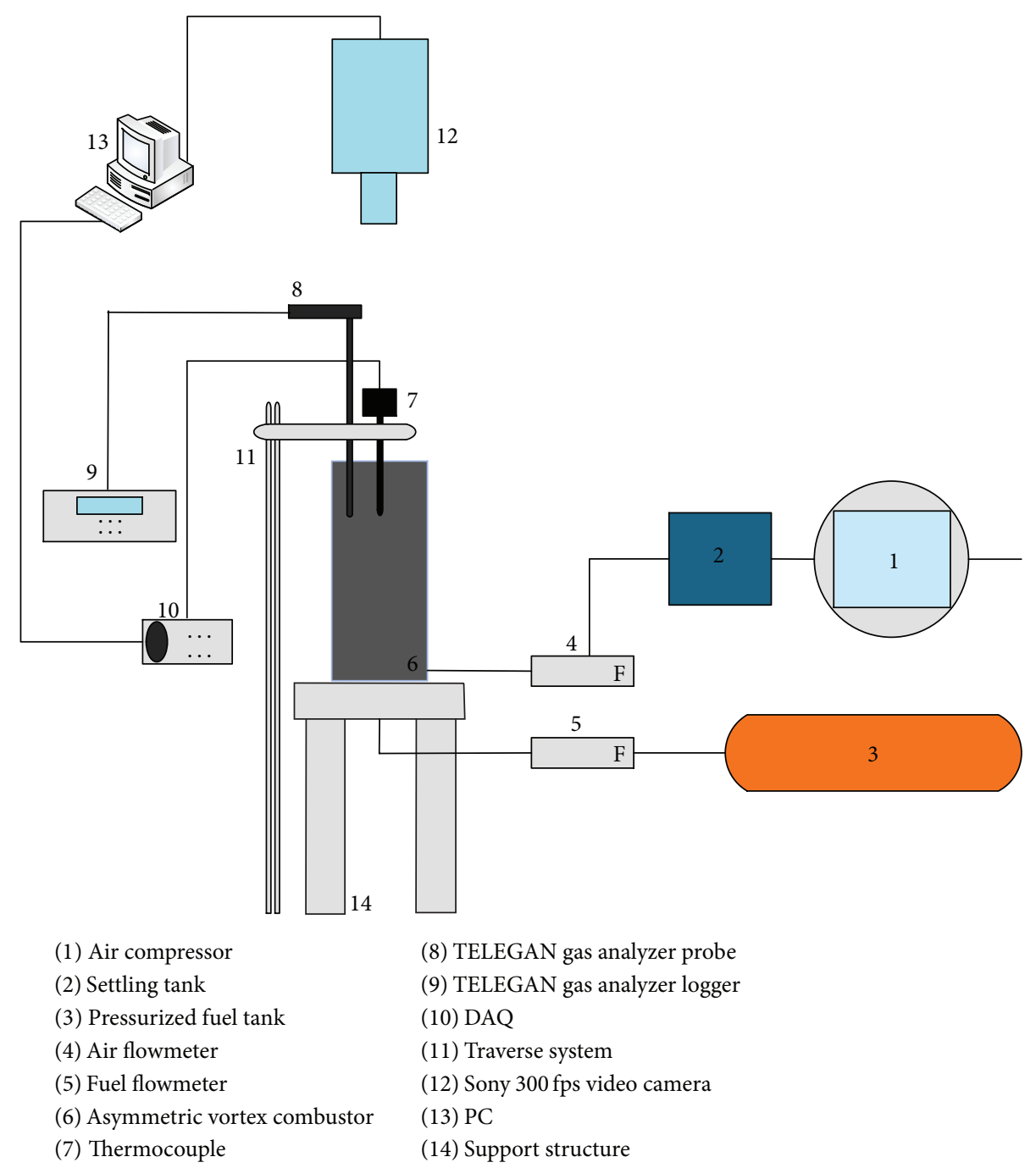

FIGURE 2: Schematic of the experimental setup of the asymmetric vortex combustor. 


$$
\begin{aligned}
\frac{\partial \rho \widetilde{u}_{i} \widetilde{Y}_{n}}{\partial x_{j}}= & \frac{\partial}{\partial x_{j}}\left[\left(\rho D_{n}+\frac{\mu_{t}}{S C_{t}}\right)\left(\frac{\partial \widetilde{Y}_{n}}{\partial x_{j}}\right)\right]+\dot{\omega}_{n}, \\
\frac{\partial \rho \widetilde{u}_{j} \widetilde{H}}{\partial x_{j}}= & \frac{\partial}{\partial x_{j}}\left[\lambda \frac{\partial \widetilde{T}}{\partial x_{j}}+\frac{\mu_{t}}{\operatorname{Pr}_{t}} \frac{\partial \widetilde{h}}{\partial x_{j}}+\sum_{n=1}^{N} \rho D_{n} h_{n} \frac{\partial \widetilde{Y}_{n}}{\partial x_{j}}\right] \\
& -\sum_{n=1}^{N} h_{n}^{f} \dot{\omega}_{n},
\end{aligned}
$$

where $\rho$ is the density, $u_{i / j}$ is the velocity vector components, $P$ is the pressure, $\lambda$ is the thermal conductivity, $\operatorname{Pr}_{t}$ is the turbulent Prandtl number, $D_{n}$ is the mass diffusivity of species $(n)$ which was assumed to be constant for each species, $Y_{n}$ is the mass fraction of species $(n), \dot{\omega}_{n}$ is the chemical reaction rate, $\mu$ is the dynamic viscosity, and $\mu_{t}$ is the turbulent viscosity. $\sim$ denotes the Favre averaging [28].

4.2. Numerical Procedures. A three-dimensional (3D) finite volume solver has been used to discretize the flow domain through a second-order upwind scheme. Several tetrahedron grids have been generated for ensuring that the solution is grid independent. The SIMPLE algorithm has been employed to achieve the mass conservation between the pressure and velocity terms in the discretized momentum equation. Chemical reaction has considered volumetric and Eddydissipation (ED) algorithm has been selected for turbulencechemistry interactions. The ED reaction model ignores chemical kinetics (i.e., the Arrhenius rate) and uses only the parameters in reaction flow. The operating pressure and temperature were set to 1.01 bars and $300 \mathrm{~K}$, respectively. The partial-equilibrium model is utilized to predict the $\mathrm{O}$ radical concentration required for thermal $\mathrm{NO}_{x}$ prediction. In all the simulations, a steady-state pressure based solver was used to solve the governing equations by CFD code ANSYS Fluent 14.0 [29].

The solution is considered to be converged when the residuals of each governing equation at consecutive iterations became less than $1 \times 10^{-3}$ except for energy equation and chemical reactions equation which are converged at quantities less than $1 \times 10^{-6}$. At such condition, the flow field variables reached stable local values with respect to any number of iterations. Also, monitor for parameters of $\mathrm{NO}_{x}$ and temperature converged separately as well. This convergence criterion was applied on reacting flow cases. The equivalence ratio, air mass flow rate, and fuel mass flow rate in all cases are constant and equal to $\varphi=0.97,0.0011 \mathrm{~kg} / \mathrm{s}$, and $6.45 \times$ $10^{-5} \mathrm{~kg} / \mathrm{s}$, respectively. The dimensions of the computational domain were similar to the full-scale actual dimensions of the asymmetric vortex combustor illustrated in Figure 3.

\subsection{Grid Testing and Model Validation}

4.3.1. Grid Independence Test. A grid independence test was performed to evaluate the effects of grid sizes on the results as shown in Figure 4. Four sets of meshes were generated using tetrahedron elements with 211,606 nodes, 375,534 nodes,

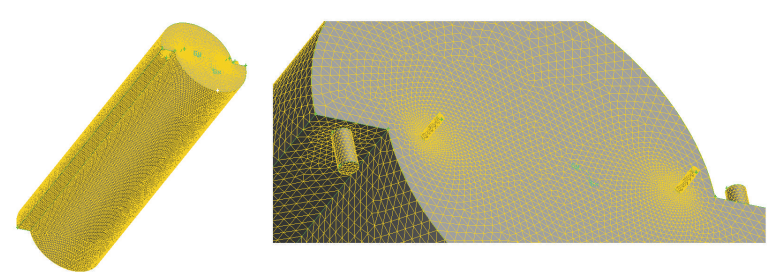

FIGURE 3: Schematic diagram of the computational domain of asymmetric vortex chamber.

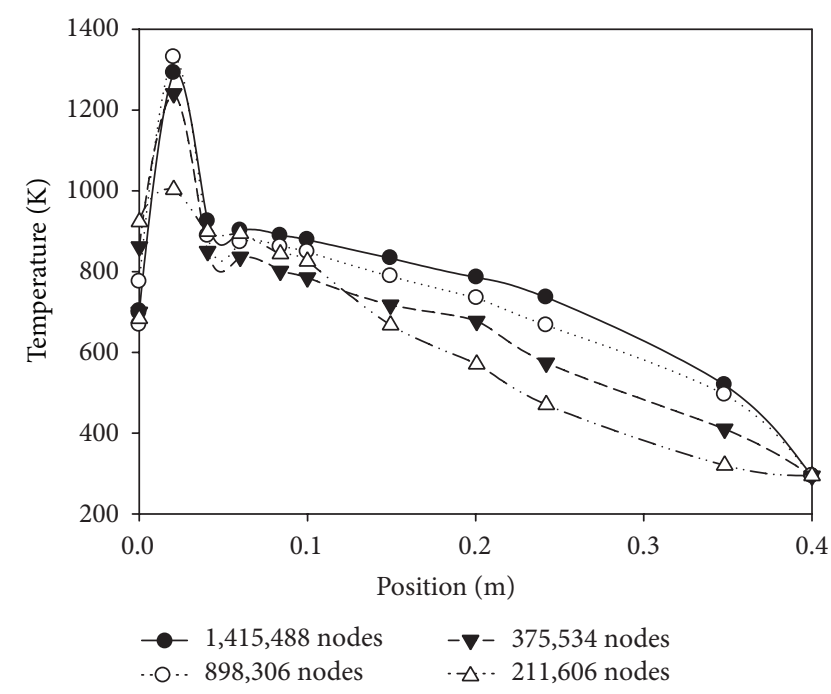

FIGURE 4: Grid independence test on the central temperature profile.

898,306 nodes, and 1,415,488 nodes. Laminar flow with counterflow configuration was considered for the fuel/oxidizer inlets at this test where the inlet air and fuel temperature were set at $300 \mathrm{~K}$. It was observed that the 375,534 nodes and 898,306 nodes produce almost identical results along the chamber with a percentage error of less than $2 \%$. Hence, a domain with 375,534 nodes was chosen to reduce the computing time.

4.3.2. Code Validation. The model validation was done based on the geometry and boundary conditions which were used by $\mathrm{Wu}$ et al. [7]. Air flows with a full tangential velocity component to the asymmetric combustor $(300 \mathrm{~K})$ and fuel flows coaxially with the center line $(300 \mathrm{~K})$. The mass flow rate for the air inlet was set to $0.0011 \mathrm{~kg} / \mathrm{s}$ and the reacting case was performed at equivalence ratios of $\varphi=0.974$. Six trials were performed with different turbulence models to compare with the experimental results. As can be seen in Figure 5, the central temperature profile is in good agreement with the experimental results when $k-\varepsilon$ RNG was chosen as turbulence model. The code was further validated by comparing the other turbulence models' results with the experimental correlation developed by Saqr and Khaleghi [30, 31]. From Figure 5, it can be seen that the temperature values fall between the accepted ranges for $k-\varepsilon$ turbulence model. 


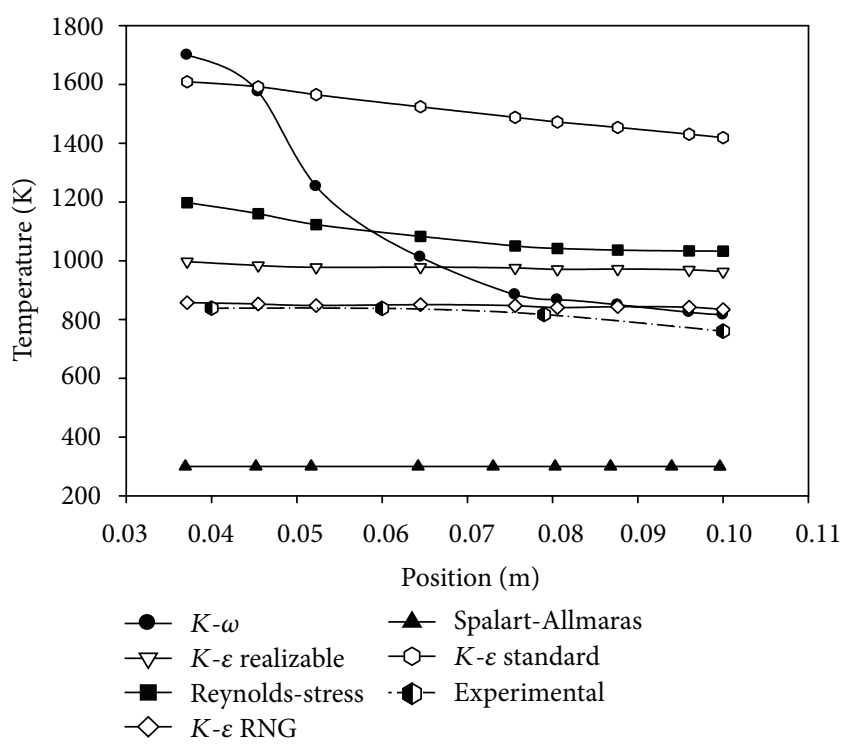

FIGURE 5: Comparison of the present results of central temperature profile along the chamber with the experimental result.

This figure clearly shows that Spalart-Allmaras could not estimate the vortex flame and also resulted in a fixed axis temperature of $300 \mathrm{~K}$. It could be observed that $k-\varepsilon$ turbulence model deviates significantly from the experimental results. Turbulence model of $k$ - $\omega$ except for region near the end of chamber was not acceptable compared to the experimental results, while the error of Reynolds-stress model is low. It is noticed that $K-\varepsilon$ realizable turbulence model had little error and $k-\varepsilon$ RNG has good adjustment with the experimental results.

\section{NO $x$ Formation Mechanisms}

5.1. Thermal and Prompt $N O_{x}$. Oxygen and nitrogen in extremely high temperature can react inside the combustion furnace according to the following reactions which are called Zeldivich formulation [32]:

$$
\begin{aligned}
& \mathrm{O}+\mathrm{N}_{2} \underset{K_{-1}}{\stackrel{K_{1}}{\rightleftharpoons}} \mathrm{NO}+\mathrm{N} \\
& \mathrm{N}+\mathrm{O}_{2} \underset{K_{-2}}{\stackrel{K_{2}}{\rightleftharpoons}} \mathrm{NO}+\mathrm{O} \\
& \mathrm{N}+\mathrm{OH} \underset{K_{-3}}{\stackrel{K_{3}}{\rightleftharpoons}} \mathrm{NO}+\mathrm{H}
\end{aligned}
$$

where $K_{1}, K_{2}$, and $K_{3}$ are forward rate constant and $K_{-1}, K_{-2}$, and $K_{-3}$ are the reverse rate constants according to Table 1 [33]. Thermal $\mathrm{NO}_{x}$ formation is accelerated exponentially according to formula (5) at temperatures more than $1500^{\circ} \mathrm{C}$ $[34,35]$ :

$$
K_{i}=A_{i} T^{B_{i}} \exp \left(\frac{-C_{i}}{T}\right)
$$

TABLE 1: Thermal $\mathrm{NO}_{x}$ reaction rate constants $\left[\mathrm{m}^{3} / \mathrm{gmol} \mathrm{s}\right.$ ].

\begin{tabular}{lc}
\hline$K_{1}$ & $\left(1.8 \times 10^{8}\right) e^{-38370 / T}$ \\
$K_{-1}$ & $\left(3.8 \times 10^{7}\right) e^{-425 / T}$ \\
$K_{2}$ & $\left(1.8 \times 10^{4}\right) T e^{4680 / T}$ \\
$K_{-2}$ & $\left(3.8 \times 10^{3}\right) T e^{-20820 / T}$ \\
$K_{3}$ & $\left(7.1 \times 10^{7}\right) e^{-450 / T}$ \\
$K_{-3}$ & $\left(1.7 \times 10^{8}\right) e^{-24560 / T}$ \\
\hline
\end{tabular}

The rate of NO formation is achieved by formula (6) when the nitrogen radical $(\mathrm{N})$ is assumed in steady-state conditions:

$$
\begin{aligned}
& \frac{d[\mathrm{NO}]}{d t} \\
& =\frac{1}{1+K_{-1}[\mathrm{NO}] /\left(K_{2}\left[\mathrm{O}_{2}\right]+K_{3}[\mathrm{OH}]\right)+2 K_{1}[\mathrm{O}]\left[\mathrm{N}_{2}\right]} \\
& \times\left[-\frac{2 K_{-1}}{K_{2}\left[\mathrm{O}_{2}\right]+K_{3}[\mathrm{OH}]} \times\left(K_{-2}[\mathrm{O}][\mathrm{NO}]\right)\right. \\
& \left.+K_{-3}[\mathrm{H}][\mathrm{NO}]\right]
\end{aligned}
$$

where $T$ is temperature $(\mathrm{K})$ and the reaction constants $A_{i}$, $B_{i}$, and $C_{i}$ were taken from Fernando et al. [33]. As there are back-and-forth reactions, it can be seen that when the rate of reaction decreases, $\mathrm{NO}_{x}$ formation declines because combustion takes place in limited time in the furnace. Moreover, $\mathrm{NO}_{x}$ constitution mitigates in low temperatures.

Prompt $\mathrm{NO}_{x}$ formation mechanism was introduced by Fenimore in 1971. Prompt or Fenimore $\mathrm{NO}_{x}$ formation occurs in fuel rich conditions (equivalence ratio greater than 1.2) [36]. The rate of prompt $\mathrm{NO}_{x}$ constitution augments near equivalence ratio of 1.4 [37].

5.2. $\mathrm{N}_{2} \mathrm{O}$ Intermediate NO Formation. Malte and Pratt [38] introduced $\mathrm{N}_{2} \mathrm{O}$ intermediate $\mathrm{NO}$ formation mechanism which occurred in lean fuel, moderate temperatures, and low pressure combustion conditions. In these circumstances $\mathrm{N}_{2} \mathrm{O}$ is converted to NO via the following formulas [39]:

$$
\begin{gathered}
\mathrm{N}_{2}+\mathrm{O}+M \longleftrightarrow \mathrm{N}_{2} \mathrm{O}+M \\
\mathrm{~N}_{2} \mathrm{O}+\mathrm{O} \longleftrightarrow \mathrm{N}_{2}+\mathrm{O}_{2} \\
\mathrm{~N}_{2} \mathrm{O}+\mathrm{O} \longleftrightarrow \mathrm{NO}+\mathrm{NO}
\end{gathered}
$$

According to Bédat and Cheng, the presence of $\mathrm{H}_{2} \mathrm{O}$ impurities conspicuously affects the $\mathrm{N}_{2} \mathrm{O}$ decomposition [40]:

$$
\begin{aligned}
\mathrm{H}_{2} \mathrm{O}+\mathrm{O} & \longleftrightarrow \mathrm{OH}+\mathrm{OH} \\
\mathrm{N}_{2} \mathrm{O}+\mathrm{OH} & \longleftrightarrow \mathrm{N}_{2}+\mathrm{H}_{2} \mathrm{O}
\end{aligned}
$$

In (7), $M$ is general third body. $\mathrm{N}_{2} \mathrm{O}$ which was constituted in (7) decomposes by (8) and (10). Equation (12) shows the chemical kinetics law for the rate of $\mathrm{NO}_{x}$ formation via $\mathrm{N}_{2} \mathrm{O}$ intermediate mechanism:

$$
\frac{d[\mathrm{NO}]}{d t}=K_{5}^{\prime}\left[\mathrm{N}_{2} \mathrm{O}\right][\mathrm{O}]-K_{6}^{\prime}[\mathrm{NO}]^{2} \text {. }
$$




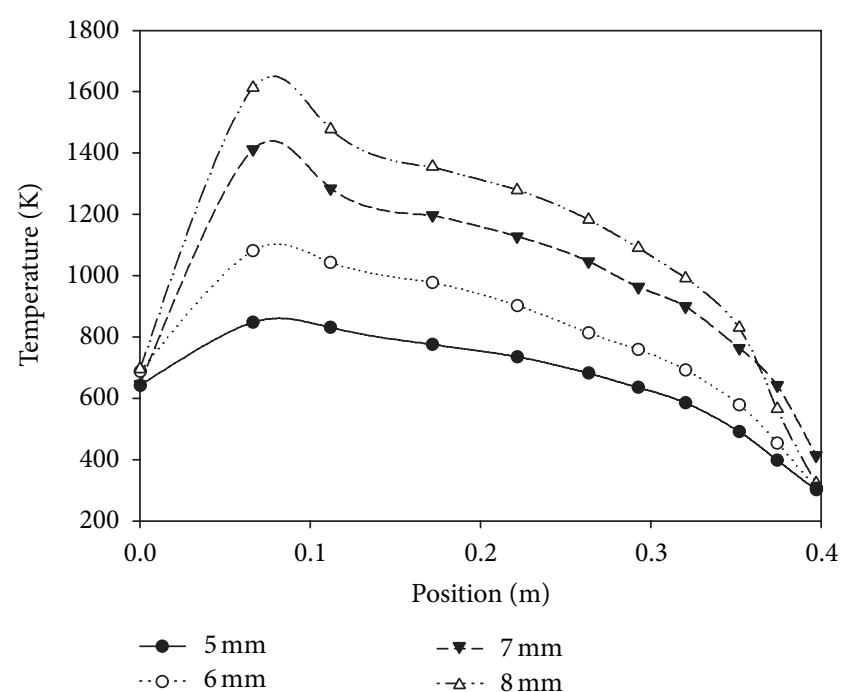

(a)
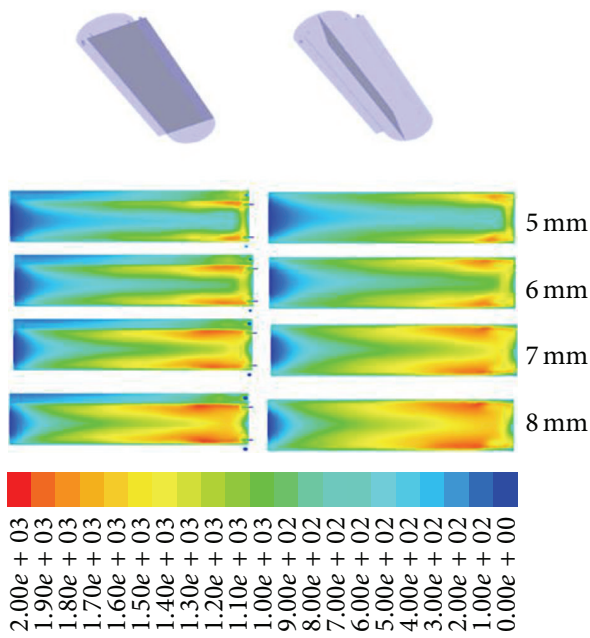

(b)

FIGURE 6: Effect of variations of air diameter on central temperature (K) profile: (a) line type and (b) contour type.

The reaction rate constants are calculated by

$$
K_{i}^{\prime}=K_{0} T^{\beta} \exp \left(-\frac{E_{a}}{R T}\right)
$$

If $d\left[\mathrm{~N}_{2} \mathrm{O}\right] / d t=0$ then (13) can be written as

$$
\begin{aligned}
& {\left[\mathrm{N}_{2} \mathrm{O}\right]} \\
& =\frac{\left[K_{1}^{\prime}\left[\mathrm{N}_{2}\right][\mathrm{O}][M]+K_{4}^{\prime}\left[\mathrm{N}_{2}\right]\left[\mathrm{O}_{2}\right]+K_{6}^{\prime}[\mathrm{NO}]^{2}+K_{8}^{\prime}\left[\mathrm{N}_{2}\right][\mathrm{OH}]\right]}{K_{2}^{\prime}[M]+\left(K_{3}^{\prime}+K_{5}^{\prime}\right)[\mathrm{O}]+K_{7}^{\prime}[\mathrm{H}]} .
\end{aligned}
$$

The concentration of radicals like $\mathrm{O}, \mathrm{OH}$, and $\mathrm{H}$ affects the concentration rates and $\mathrm{NO}$ constitution [41]. $\mathrm{N}_{2} \mathrm{O}$ intermediate $\mathrm{NO}$ formation increases in low oxygen concentration conditions [42].

5.3. Fuel-Bond $\mathrm{NO}_{x}$ Formation Mechanism. Fuel-bond $\mathrm{NO}_{x}$ formation mechanism occurs when the molecular structures of the fuel are constituted by nitrogen species. In the combustion of these fuels the nitrogen atoms are decomposed to intermediate products form which can react with $\mathrm{NO}_{x}$ [43].

\section{Results and Discussion}

6.1. The Influence of Inlet Air Diameter on the Characteristics of Vortex Combustion. The effect of inlet air diameter changing on the performance of vortex combustion is analyzed while the mass flow of fuel and air is kept constant. Therefore, the equivalence ratio was constant and equal to 0.974 . Figure 6(a) depicts the effect of inlet diameter changing on the static temperature along the centerline with respect to the constant mass flow rate. The temperature increases along the central axis due to the heat released by reactions. For larger inlet air diameter, the temperature first sharply increases and then decreases along the axial direction. Figure 6(b) demonstrates the temperature contours in two various surfaces. There are

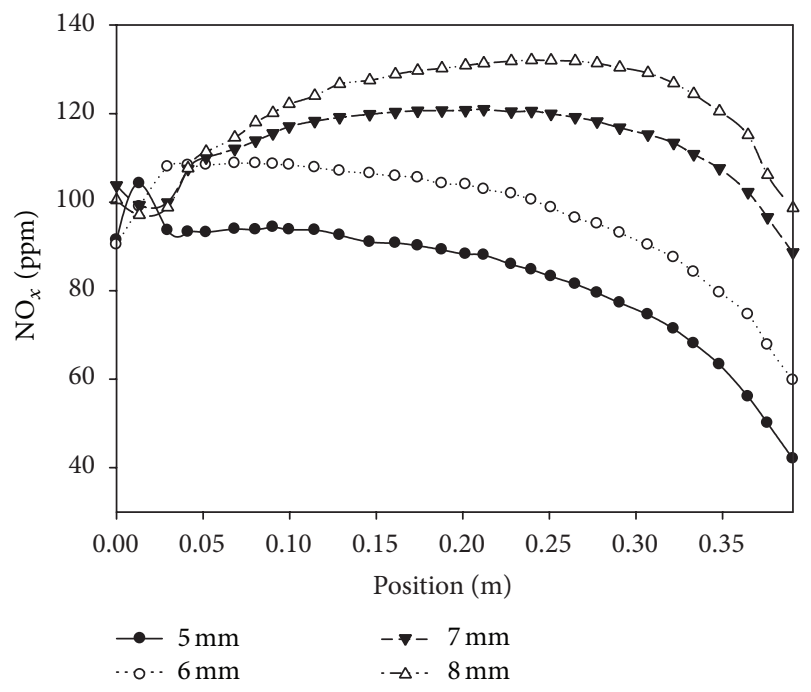

FIGURE 7: Effect of air diameter variation on the central $\mathrm{NO}_{x}$ profile.

obvious differences in these contours. From this figure, it can be interpreted that increasing in inlet air diameter with constant mass flow rate (decreasing inlet velocity) leads to increase in residence time. The decrease of speed of vortex flame and diffusion of flame to the center of chamber are the two original reasons of these changes.

The effect of diameter variation on the flame structure showed that the $\mathrm{NO}_{x}$ value on the centerline of the chamber increased when the inlet air diameter increased as shown in Figure 7. It should be noted that the $\mathrm{NO}_{x}$ concentration increased with the increase of air inlet diameter due to increase of the excess air and flame high temperature as shown in Figure 8 and Table 2. It is concluded that $\mathrm{NO}_{x}$ formation (Based on Zeldovich equations) is mainly controlled by temperature of combustion. 
TABLE 2: Average outlet quantity of chamber.

\begin{tabular}{lcc}
\hline Inlet air diameter & Average $\mathrm{NO}_{x}$ outlet & $\begin{array}{c}\text { Average temperature } \\
\text { outlet }\end{array}$ \\
\hline 5 & 72 & 470 \\
6 & 82 & 500 \\
7 & 95 & 535 \\
8 & 98 & 568 \\
\hline
\end{tabular}

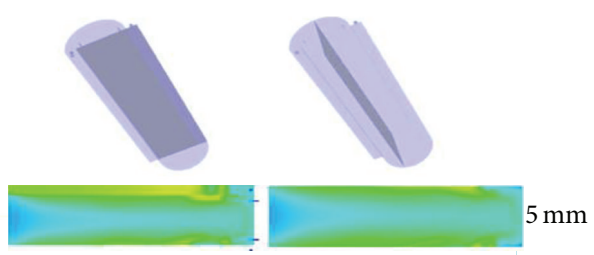

(a)
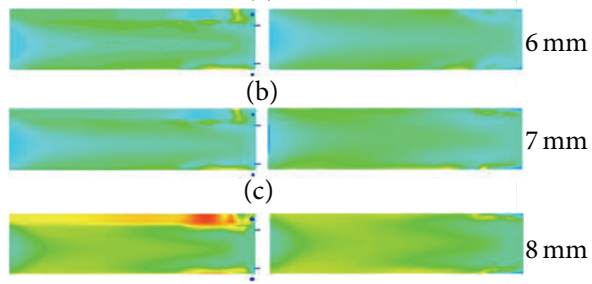

(d)

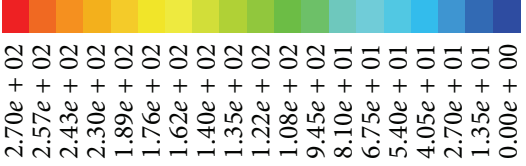

FIGURE 8: $\mathrm{NO}_{x}$ emissions (ppm) contour for different air diameters: (a) $d=5 \mathrm{~mm}$, (b) $d=6 \mathrm{~mm}$, (c) $d=7 \mathrm{~mm}$, and (d) $d=8 \mathrm{~mm}$.

6.2. The Effect of Inlet Fuel Diameter on the Characteristics of Vortex Combustion. Figure 9 illustrates the trend of $\mathrm{NO}_{x}$ formation and temperature distribution along with the chamber length with respect to the various fuel diameters $(2,2.5,3,3.5$, and $4 \mathrm{~mm}$ ). From this figure, it can be construed that the size of the fuel inlet has insignificant effect on the $\mathrm{NO}_{x}$ formation and static temperature. This shows that temperature flame as well as $\mathrm{NO}_{x}$ emission in the chamber has more effect on inlet air compared to inlet fuel; in other words, the inlet fuel velocity has negligible contribution to vortex flames compared to air inlet velocity.

6.3. Preheating Air Effects. Figure 10 shows temperature distribution and $\mathrm{NO}_{x}$ emissions formation when oxidizer is applied in four different air temperatures $(T=300 \mathrm{~K}, 400 \mathrm{~K}$, $500 \mathrm{~K}$, and $600 \mathrm{~K}$ ) while the diameter of the air and fuel inlet, the mass flow rate of air and fuel inlet, and equivalence ratio are kept constant at $5 \mathrm{~mm}, 2 \mathrm{~mm}, 0.0011 \mathrm{~kg} / \mathrm{s}, 6.45 \times 10^{-5} \mathrm{~kg} / \mathrm{s}$, and 0.97 , respectively. All of the predictions are performed at the same central axis location with the above discussed conditions. It was found that increasing the preheating air temperature and decreasing the air viscosity could limit the maximum flame temperature and improve the temperature

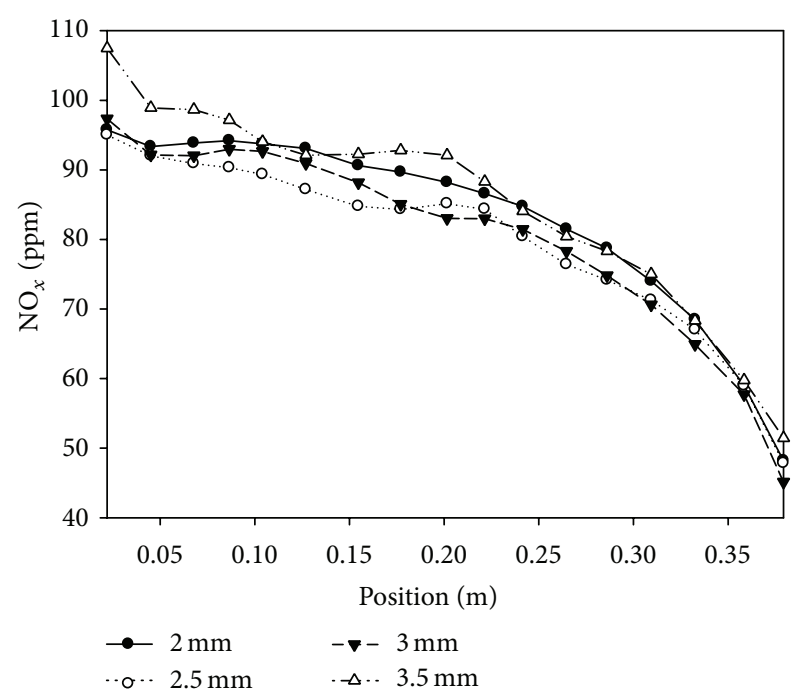

(a)

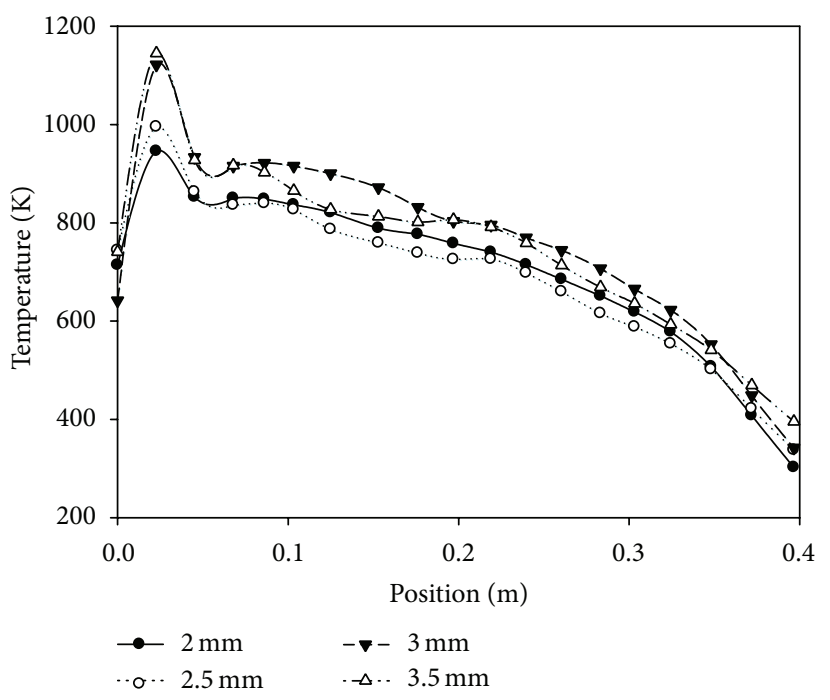

(b)

FIGURE 9: Effect of variations of fuel diameter on central (a) $\mathrm{NO}_{x}$ profile and (b) temperature profile.

uniformity in the furnace. The data shows that, with increasing preheating air at a constant mass flow rate, the flame location moves toward the air inlet because the momentum of the air stream decreases. Because the flame tends to approach the wall, the temperature along the central axis decreases with increase of air inlet temperature. As a result, the $\mathrm{NO}_{x}$ emission decreases when the flame temperature decreases.

6.4. Preheating Fuel Effects. Figures 11 and 12 show a minimum effect of preheating fuel on the flame characteristics such as static temperature and $\mathrm{NO}_{x}$ emissions. The temperature and oxygen mole fraction of air kept constant and equal to $300 \mathrm{~K}$ and $20 \%$, respectively. It can be seen that the temperature along the central axis of the combustion chamber has no significant change with increasing of the fuel temperature. In 


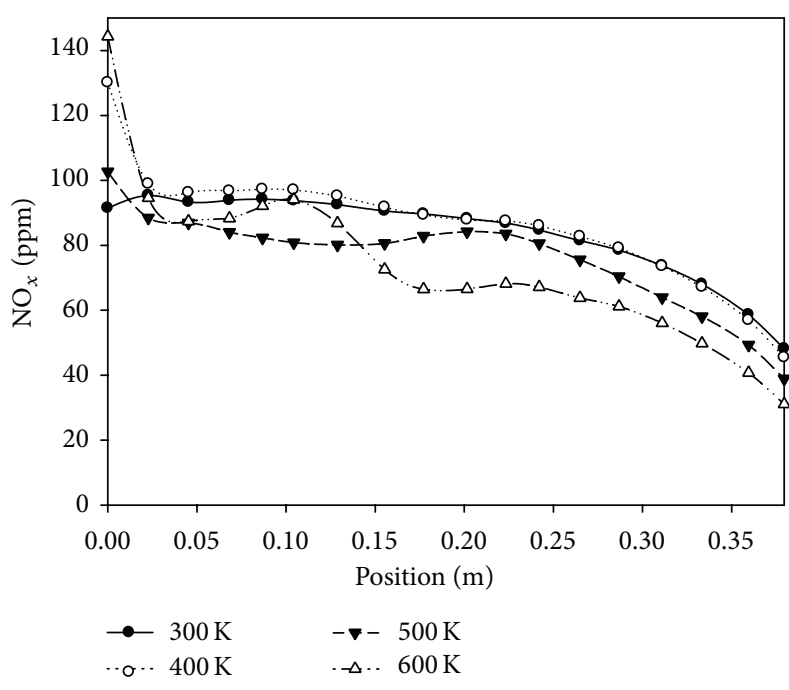

(a)

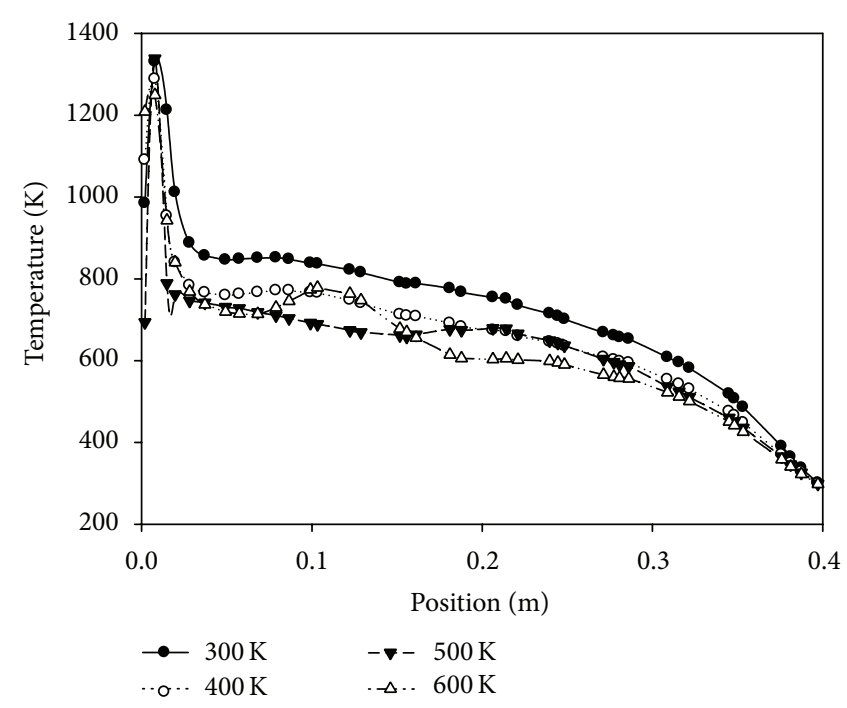

(b)

FIGURE 10: Effect of preheating air on the central (a) $\mathrm{NO}_{x}$ profile and (b) temperature profile.

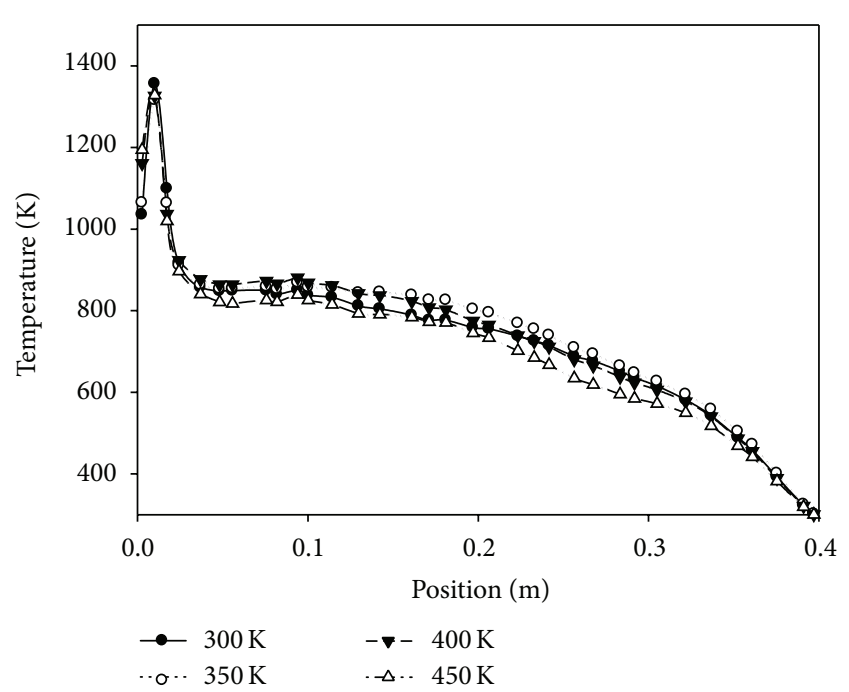

FIGURE 11: The effect of preheating fuel on the central temperature profile.

addition, the results show that, at all fuel temperatures, the temperature decreases along the combustion chamber due to recession of flame and design of exhaust chamber. The maximum temperature is found in the vicinity of the bottom wall, where the fuel enters the combustion chamber. The results reveal that preheating inlet fuel has insignificant effect on the maximum flame temperature.

Figure 12 shows that the $\mathrm{NO}_{x}$ emission rises as the maximum flame temperature increases. With the increase of the fuel temperature at a fixed air flow rate there is a high temperature mixing in the flame zone, so there will be more thermal $\mathrm{NO}_{x}$ products with the fuel and increases in the temperature. The increased $\mathrm{NO}_{x}$, caused by fuel preheating, is consistent with the hypothesis that preheating levels of $300 \mathrm{~K}$, $500 \mathrm{~K}$, and $700 \mathrm{~K}$ enhance fuel pyrolysis rates.

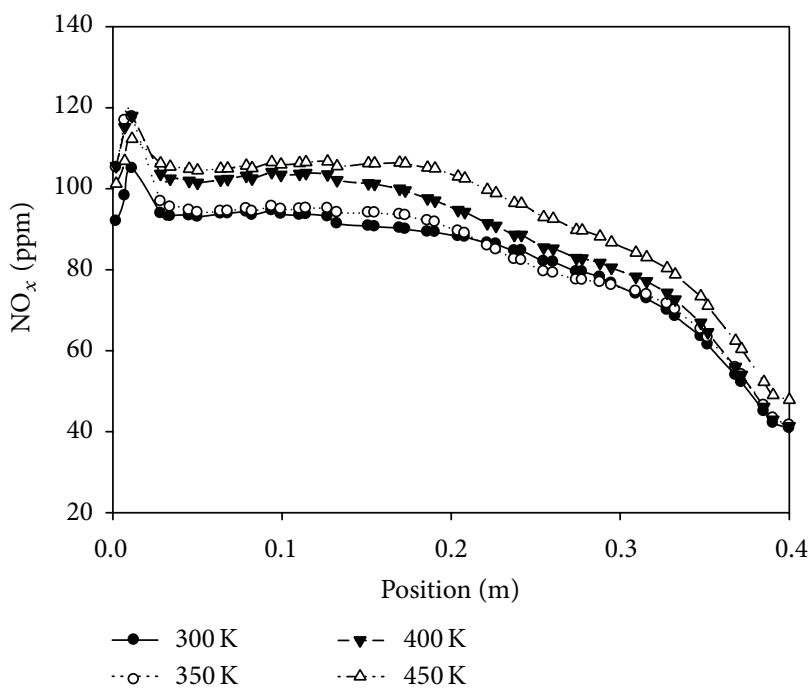

FIgURE 12: The effect of preheating fuel on the central $\mathrm{NO}_{x}$ profile.

\section{Conclusions}

A computational study on the performance of asymmetric vortex flame for various inlet flow diameters (air and fuel) and effect of preheating air and fuel was analyzed. The results showed that increasing the inlet fuel diameter has negligible effect on the flame compared to effect of increasing inlet air to flame temperature and $\mathrm{NO}_{x}$ emission. The thermal field results show that the effect of preheating can attain lowemission $\mathrm{NO}_{x}$ as compared to fuel. It is found that increasing the preheated air temperature and fuel temperature could decrease the flame temperature and the combustion intensity and $\mathrm{NO}_{x}$ emission, when the air mass flow rate, fuel mass flow rate, and equivalence ratio were considered constant for all simulations. Increasing the air velocity due to preheated air 
in constant mass flow rate and equivalence ratio is found to be an effective way to control the $\mathrm{NO}_{x}$ emission because of the decrease of the flame temperature.

\section{Nomenclature}

\author{
$d$ : Chamber diameter ( $\mathrm{mm})$ \\ $D_{n}$ : Mass diffusivity $\left(\mathrm{m}^{2} / \mathrm{s}\right)$ \\ $L: \quad$ Length of chamber ( $\mathrm{mm})$ \\ $m$ : Air and fuel mass flow rate $(\mathrm{kg} / \mathrm{s})$ \\ $p: \quad$ Pressure (pa) \\ $\mathrm{Pr}_{t}$ : Prandtl number \\ Re: Reynolds number $(\operatorname{Re}=\rho u d / \mu)$ \\ $T$ : $\quad$ Temperature (K) \\ $u_{i / j}$ : Velocity vector component $(\mathrm{m} / \mathrm{s})$ \\ $Y_{n}$ : Mass fraction of species $n$.
}

\section{Greek Symbols}

$\lambda:$ Thermal conductivity $(\mathrm{W} /(\mathrm{m} \cdot \mathrm{K}))$

$\mu: \quad$ Dynamic viscosity $(\mathrm{kg} / \mathrm{m} \cdot \mathrm{s})$

$\mu_{t}$ : Turbulent viscosity $(\mathrm{kg} / \mathrm{m} \cdot \mathrm{s})$

$\rho:$ Density $\left(\mathrm{kg} / \mathrm{m}^{3}\right)$

$\varphi$ : Equivalence ratio

$\dot{\omega}_{n}$ : Chemical reaction rate.

\section{Conflict of Interests}

The authors declare that there is no conflict of interests regarding the publication of this paper.

\section{References}

[1] S. E. Hosseini, M. A. Wahid, and A. A. A. Abuelnuor, "High temperature air combustion: sustainable technology to low NOx formation," International Review of Mechanical Engineering, vol. 6, no. 5, pp. 947-953, 2012.

[2] R. K. Srivastava, R. E. Hall, S. Khan, K. Culligan, and B. W. Lani, "Nitrogen oxides emission control options for coal-fired electric utility boilers," Journal of the Air and Waste Management Association, vol. 55, no. 9, pp. 1367-1388, 2005.

[3] R. K. Srivastava, W. Neuffer, D. Grano, S. Khan, J. E. Staudt, and W. Jozewicz, "Controlling $\mathrm{NO}_{x}$ emission from industrial sources," Environmental Progress, vol. 24, no. 2, pp. 181-197, 2005.

[4] M. Khaleghi, S. E. Hosseini, and M. Abdul Wahid, "Investigations of asymmetric non-premixed meso-scale vortex combustion," Applied Thermal Engineering, vol. 81, pp. 140-153, 2015.

[5] D. Feikema, R. H. Chen, and J. F. Driscoll, "Enhancement of flame blowout limits by the use of swirl," Combustion and Flame, vol. 80, no. 2, pp. 183-195, 1990.

[6] H. Gabler, An Experimental and Numerical Investigation of Asymmetrically-Fueled Whirl Flames, Princeton University, 1998.

[7] M.-H. Wu, Y. Wang, V. Yang, and R. A. Yetter, "Combustion in meso-scale vortex chambers," Proceedings of the Combustion Institute, vol. 31, pp. 3235-3242, 2007.

[8] M. Khaleghi, M. A. Wahid, M. M. Seis, and A. Saat, "Investigation of vortex reacting flows in asymmetric Meso scale combustor," Applied Mechanics and Materials, vol. 388, pp. 246250, 2013.

[9] K. R. McManus, T. Poinsot, and S. M. Candel, "A review of active control of combustion instabilities," Progress in Energy and Combustion Science, vol. 19, no. 1, pp. 1-29, 1993.

[10] S. Candel, "Combustion dynamics and control: progress and challenges," Proceedings of the Combustion Institute, vol. 29, no. 1, pp. 1-28, 2002.

[11] Y. Huang and V. Yang, "Dynamics and stability of leanpremixed swirl-stabilized combustion," Progress in Energy and Combustion Science, vol. 35, no. 4, pp. 293-364, 2009.

[12] T. C. Lieuwen and V. Yang, Combustion Instabilities in Gas Turbine Engines: (Operational Experience, Fundamental Mechanisms, and Modeling), Progress in Astronautics and Aeronautics, American Institute of Aeronautics and Astronautics, 2005.

[13] B. Kapadia and P. Kutne, "Combustion behavior of swirl stabilised oxyfuel flames at elevated pressure," in Proceedings of the 9th AIAA Annual International Energy Conversion Engineering Conference (IECEC '11), AIAA-5593, San Diego, Calif, USA, July-August 2011.

[14] P.-H. Renard, D. Thévenin, J. C. Rolon, and S. Candel, "Dynamics of flame/vortex interactions," Progress in Energy and Combustion Science, vol. 26, no. 3, pp. 225-282, 2000.

[15] M. Stöhr, I. Boxx, C. Carter, and W. Meier, "Dynamics of lean blowout of a swirl-stabilized flame in a gas turbine model combustor," Proceedings of the Combustion Institute, vol. 33, no. 2, pp. 2953-2960, 2011.

[16] M. R. Johnson, D. Littlejohn, W. A. Nazeer, K. O. Smith, and R. K. Cheng, "A comparison of the flowfields and emissions of high-swirl injectors and low-swirl injectors for lean premixed gas turbines," Proceedings of the Combustion Institute, vol. 30, pp. 2867-2874, 2005.

[17] P. K. Ezhil Kumar and D. P. Mishra, "Numerical investigation of the flow and flame structure in an axisymmetric trapped vortex combustor," Fuel, vol. 102, pp. 78-84, 2012.

[18] J. Yuan and I. Naruse, "Effects of air dilution on highly preheated air combustion in a regenerative furnace," Energy \& Fuels, vol. 13, no. 1, pp. 99-104, 1999.

[19] J. B. Bell, N. J. Brown, M. S. Day, M. Frenklach, J. F. Grcar, and S. R. Tonse, "The dependence of chemistry on the inlet equivalence ratio in vortex-flame interactions," Proceedings of the Combustion Institute, vol. 28, no. 2, pp. 1933-1939, 2000.

[20] J. Beer, Combustion Aerodynumics, Combustion Technology: Some Modern Developments, 2012.

[21] A. K. Gupta and D. G. Lilley, Flowfield Modeling and Diagnostics, Taylor \& Francis, London, UK, 1985.

[22] J. J. Choi, Z. Rusak, and A. K. Kapila, "Numerical simulation of premixed chemical reactions with swirl," Combustion Theory and Modelling, vol. 11, no. 6, pp. 863-887, 2007.

[23] N. Syred, "A review of oscillation mechanisms and the role of the precessing vortex core (PVC) in swirl combustion systems," Progress in Energy and Combustion Science, vol. 32, no. 2, pp. 93-161, 2006.

[24] M. Stöhr, I. Boxx, C. D. Carter, and W. Meier, "Experimental study of vortex-flame interaction in a gas turbine model combustor," Combustion and Flame, vol. 159, no. 8, pp. 26362649, 2012.

[25] M. Stöhr, R. Sadanandan, and W. Meier, "Phase-resolved characterization of vortex-flame interaction in a turbulent swirl flame," Experiments in Fluids, vol. 51, no. 4, pp. 1153-1167, 2011. 
[26] K. M. Saqr, H. S. Aly, M. M. Sies, and M. A. Wahid, "Computational and experimental investigations of turbulent asymmetric vortex flames," International Communications in Heat and Mass Transfer, vol. 38, no. 3, pp. 353-362, 2011.

[27] A. Obieglo, J. Gass, and D. Poulikakos, "Comparative study of modeling a hydrogen nonpremixed turbulent flame," Combustion and Flame, vol. 122, no. 1-2, pp. 176-194, 2000.

[28] K. M. Saqr, M. M. Sies, and M. A. Wahid, "Numerical investigation of the turbulence-combustion interaction in nonpremixed $\mathrm{CH}_{4}$ /air flames," International Journal of Applied Mathematics and Mechanics, vol. 5, no. 8, pp. 69-79, 2009.

[29] ANSYS, ANSYS FLUENT User's Guide, ANSYS, Canonsburg, $\mathrm{Pa}$, USA, 2011.

[30] K. M. Saqr, H. S. Aly, M. M. Sies, and M. A. Wahid, "Effect of free stream turbulence on NOx and soot formation in turbulent diffusion CH4-air flames," International Communications in Heat and Mass Transfer, vol. 37, no. 6, pp. 611-617, 2010.

[31] M. Khaleghi, S. E. Hosseini, and M. A. Wahid, "Emission and combustion characteristics of hydrogen in vortex flame," Jurnal Teknologi, vol. 66, no. 2, pp. 47-51, 2014.

[32] C. T. Bowman, "Kinetics of pollutant formation and destruction in combustion," Progress in Energy and Combustion Science, vol. 1, no. 1, pp. 33-45, 1975.

[33] S. Fernando, C. Hall, and S. Jha, "NOx reduction from biodiesel fuels," Energy \& Fuels, vol. 20, no. 1, pp. 376-382, 2006.

[34] W. C. Gardiner, Ed., Gas-Phase Combustion Chemistry, Springer, New York, NY, USA, 2000.

[35] G. Lavoie, J. Heywood, and J. Keck, "Experimental and theoretical study of nitric oxide formation in internal combustion engines," Combustion Science and Technology, vol. 1, no. 4, pp. 313-326, 1970.

[36] C. P. Fenimore, "Formation of nitric oxide in premixed hydrocarbon flames," Symposium (International) on Combustion, vol. 13, no. 1, pp. 373-380, 1971.

[37] L. Pillier, A. El Bakali, X. Mercier et al., "Influence of $\mathrm{C}_{2}$ and $\mathrm{C}_{3}$ compounds of natural gas on $\mathrm{NO}$ formation: an experimental study based on LIF/CRDS coupling," Proceedings of the Combustion Institute, vol. 30, pp. 1183-1191, 2005.

[38] P. C. Malte and D. T. Pratt, "Measurement of atomic oxygen and nitrogen oxides in jet-stirred combustion," pp. 1061-1070, 1975.

[39] G. Löffler, V. J. Wargadalam, F. Winter, and H. Hofbauer, "Decomposition of nitrous oxide at medium temperatures," Combustion and Flame, vol. 120, no. 4, pp. 427-438, 2000.

[40] B. Bédat and R. K. Cheng, "Experimental study of premixed flames in intense isotropic turbulence," Combustion and Flame, vol. 100, no. 3, pp. 485-494, 1995.

[41] A. Khoshhal, M. Rahimi, and A. A. Alsairafi, "CFD study on influence of fuel temperature on NOx emission in a HiTAC furnace," International Communications in Heat and Mass Transfer, vol. 38, no. 10, pp. 1421-1427, 2011.

[42] W. Yang and W. Blasiak, "Mathematical modelling of NO emissions from high-temperature air combustion with nitrous oxide mechanism," Fuel Processing Technology, vol. 86, no. 9, pp. 943-957, 2005.

[43] I. Glassman, Combustion, Academic Press, 1997. 


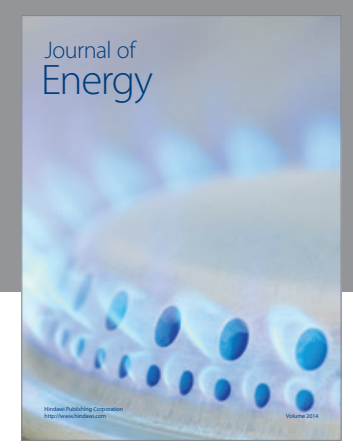

Journal of

Industrial Engineering
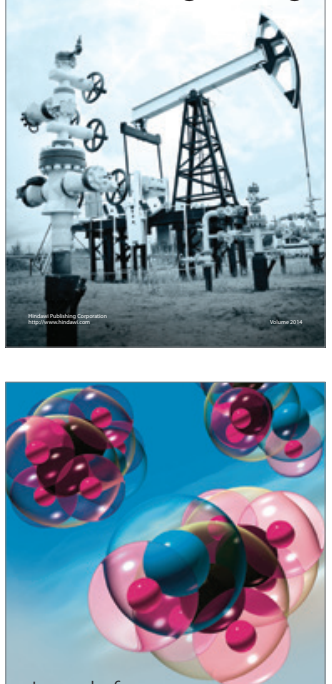

Fuels
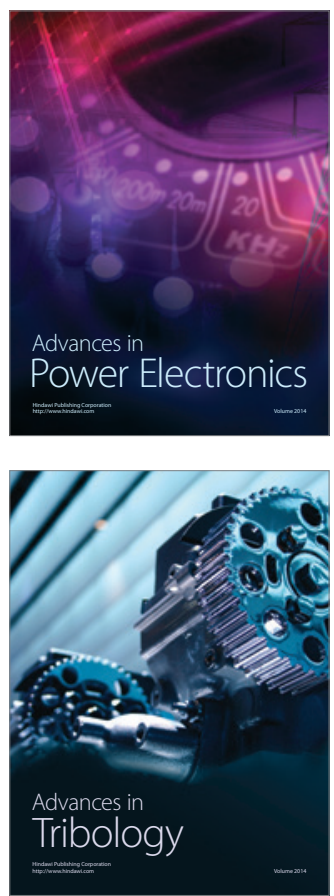

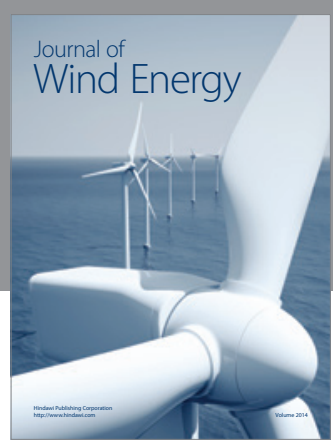

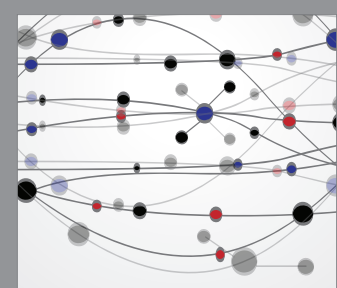

The Scientific World Journal

Submit your manuscripts at http://www.hindawi.com

Journal of

Structures
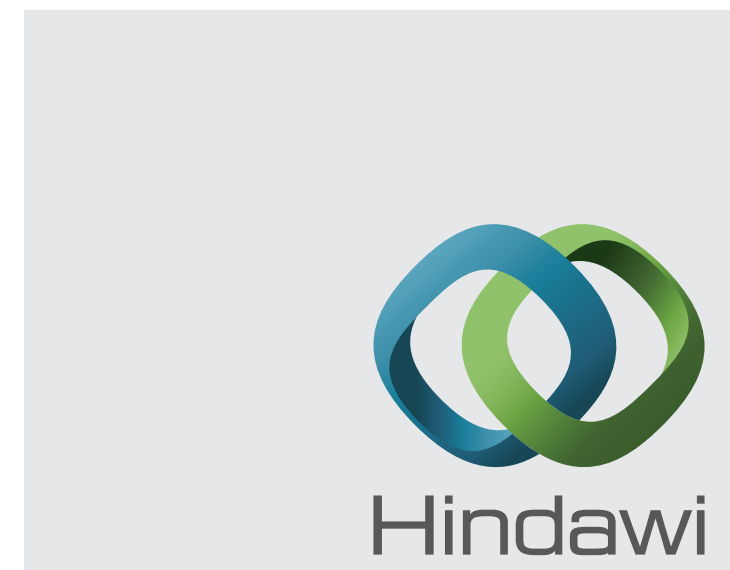

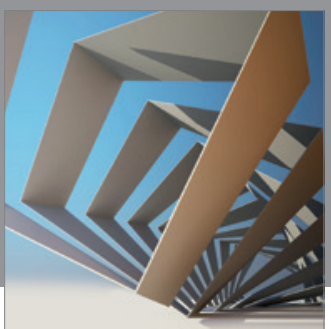

Rotating

Machinery
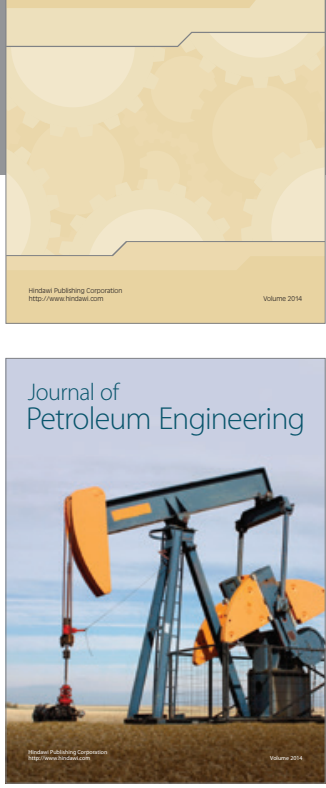

Journal of

Solar Energy
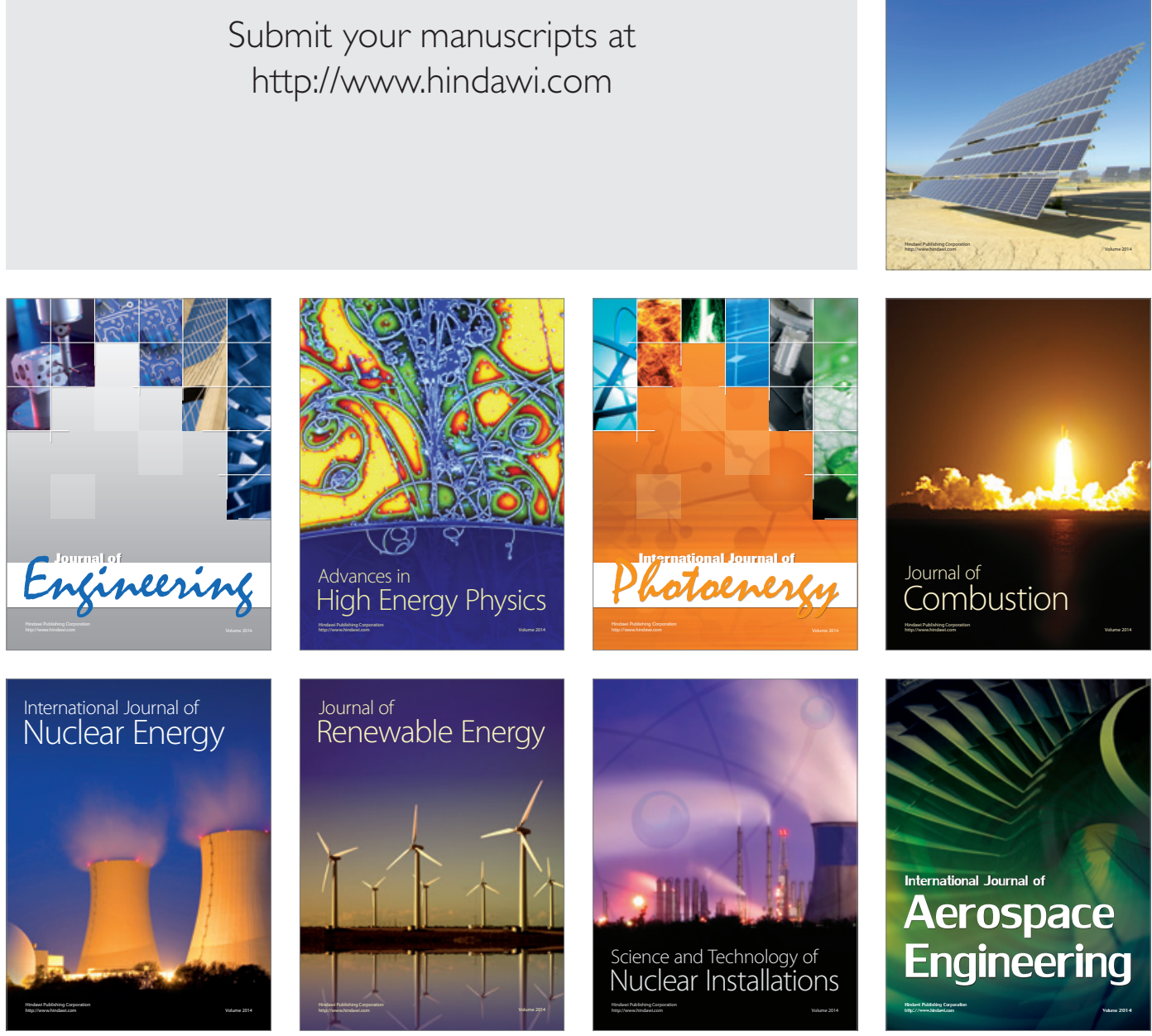